\title{
International Migrant Labors in Tourism and Hospitality: Developing a Framework of Motivational Pull Factors
}

\author{
${ }^{1}$ Nurhazani Mohd. Shariff, ${ }^{2}$ Azlan Zainol Abidin, ${ }^{3}$ Nur Syafiqah Abd. Ghani, ${ }^{4}$ Titing Kartika \\ ${ }_{123}$ School of Tourism, Hospitality \& Event Management, UUM COLGIS, Universiti Utara Malaysia, 06010 Sintok, Kedah, Malaysia \\ ${ }^{2}$ School of Languages, Civilization \& Philosophy, UUM CAS, Universiti Utara Malaysia, 06010, Sintok, Kedah, Malaysia \\ ${ }^{4}$ Sekolah Tinggi Ilmu Ekonomi Pariwisata Yapari, 40152 Bandung, Indonesia
}

Correspondence Author: Associate Professor Dr Nurhazani Mohd Shariff, School of Tourism, Hospitality \& Event Management, UUM COLGIS, Universiti Utara Malaysia, 06010 Sintok, Kedah, Malaysia.

6012-5569004; E-mail: hazani@uum.edu.my

Received date: 23 March 2018, Accepted date: 25 April 2018, Online date: 25 May 2018

Copyright: (c) 2018 Tauane Santos Brito et al. This is an open-access article distributed under the terms of the Creative Commons Attribution License, which permits unrestricted use, distribution, and reproduction in any medium, provided the original author and source are credited.

\begin{abstract}
Background: International migrant labors play essential roles in the service industry particularly for tourism and hospitality. Their arrivals in the industry have contributed to the gap of fulfilling employment issues. Most sectors within the industry for instance restaurant, accommodation and transportation are recruiting the international migrant labors to fulfill several positions including the unskilled, semi-skilled and professionals. Objective: There is lack of study on international migrant labors in the tourism and hospitality industry particularly relating to motivational factors. Hence, the main objective of the paper is to identify the pull factors which motivate international migrant labors to work in the tourism and hospitality industry. The study involved exploratory research where significant literature on pull factors motivating the international migrant labors to work within the industry were reviewed. Results: Based from previous studies, the framework highlights several factors namely high wages, better employment, better facilities, opportunity for career growth and job security as five major pull factors motivating the international migrant labors to work in the tourism and hospitality industry. Conclusion: The framework is considered as an advance contribution to the industry in terms of understanding the most vital motivational factors which pull the international migrant labors to work in the industry. These identified factors would also contribute to further research in determining whether they significantly motivate the international migrant labors to work in the industry. Further, taking these factors into account would assist the human resource managers in the industry to plan for effective positions to be fulfilled by the international migrant labors.
\end{abstract}

Key words: International migrant, labors, motivational pull factor, tourism, hospitality

\section{INTRODUCTION}

Migrant labor is seen as all those who travel for employment reasons either for longer term settlement or those who are recruited for a contracted period of time (Athukorala, 1990). Yee and Yuen (2014)define migrant labor as a foreigner who is involved or has been involved in a waged doings in a state of which he or she is not a citizen.Several studies indicate that international migrant labors play vital role as they contribute to better employment for such country (Masseyet al., 1993; Mayda, 2007; Cerdinet al., 2014; Yee and Yuen, 2014). Besides its contribution to the employment of labors, Ramasamy (2014) emphasizes that migration of people from one country to another has turned out to be a social development process which incidentally given an impact in the context of economy. Further, Ajis et al. (2014) also highlight that international migrant labors are the major source of workforce in the development of an economy.

As for the tourism and hospitality industry in Asia, the arrival of international labors to look for jobs is tremendously increased (Mohamed et al., 2016). In the case of Malaysia for instance, it can be seen that the tourism small and medium-sized enterprises recruited almost 991,419 labors, hence indicated the needs to recruit international labors (ZainolAbidin et al., 2016). Additionally, according to Ajis et al. (2014), the countries in Asia can be considered as the major contributors of foreign immigrants, especially in the context of employment in this world. It is a fact that the international migrant labors are needed in the industry. For example in the South African hospitality sector, one of the reasons that migrants preferred to work in the industry is because they are desperate to work for gaining income (Vettori, 2017).

\section{Background of the study:}

According to the International Organization for Migration (IOM, 2010), Malaysia, Singapore and destination countries in the Middle East desire and require labor forces that are low skilled or willing to embark on low-skilled jobs that their citizens are unwilling to take at the usual wages. Additionally, Patricia (2010) highlights that the involvement of international migrant labors are also seen as more of a substitute to complete the vacancies in certain sectors which the locals are not interested to work in, rather than something permanent. The study in Southeast Asia, shows that Singapore provides the highest number of international migrants with 1.8 million, and follows by Malaysia with 1.6 million.

In the context of tourism and hospitality, migration can be seen through the creation of employment opportunities (Connell, 1987). Several other researchers also support this study by emphasizing that international migrants have formed a significant part of tourism and hospitality workforce (Choiet al., 2000; Williams and Hall, 2000; Baum, 2012). Previously, most researches (Varley, 1978; Cukier-Snow and Wall, 1993; Sharpley, 1994) indicate that majority of direct employment opportunities in the tourism and hospitality sector are seasonal or part-time, or both, and that only two out of every five jobs have provided full-time, year-round employment. The contribution of international migrant labors in the tourism and hospitality industry is also emphasized in a study by Williams and Hall (2000). The study highlights that the production and consumption of tourism and hospitality services have also produced migration in terms of skill and educational requirements. 


\section{Problem statement and objective:}

Today, one of the dilemmas facing the tourism and hospitality labor market is lack of information on the nature of employment. As tourism and hospitality is a new industry in many areas, it is quite likely that individuals have a limited understanding of what employment alternatives exist, or what the quality of work is like. Literature on tourism and hospitality employment also emphasize that the quality of employment created is difficult to assess (Sharpley, 1994). Since tourism and hospitality industry brings about migration within the labor force, through the creation of employment opportunities, it is very important to identify and deeply understand the pull factors which motivate the international migrant labors to work in the industry. As this is an exploratory study to really understand the scenario, the primary information is gained by reviewing previous literature regarding pull factors. It involves library research including report from the specific department and organization regarding international migrant labors. Hence, the objective of this paper is to present a framework of the pull factors which motivate the international migrant labors to work in the tourism and hospitality industry.

\section{Literature Review:}

This section discusses three major aspects concerning the topic. Firstly, it defines the various meaning of international migrant labors. It then follows by explaining the international migrant labors in tourism and hospitality industry. Finally it describes the pull factors which motivate the international migrant labors to work in the tourism and hospitality industry.

\section{Defining International Migrant Labors:}

The first phase in defining international labor is to understand the meaning of migration. Various definitions of migration are discussed in literature. In a complex term, Mejia et al. (1979) define migration as the result of the interplay of various forces at both ends of the migratory axis. Kainth (2009) additionally describes migration at macro level as a global phenomenon encourage in the form of inter-regional and intraregional disparities. Whilst at the micro level, migration also occurs due to lack of employment opportunities and low standard of living conditions among different socio-economic groups.

According to Rachbini (1991), on the level of the individual, migration can be seen as an investment in human resources and is often motivated by low levels of income in rural areas. Further, migration is also seen as the movement of people (voluntary and forced) across borders and usually driven by either economic need or social reasons (Knipscheer and Kleber, 2007). Additionally, the United Nations (2009) defines migrant labor as a foreigner who is involved or has been involved in a waged activity in a nation of which he or she is not a citizen. Migration in the context of labor movement is also known as 'labor mobility'. It refers to the freedom of workers to practice their occupation wherever opportunities exist. Hence, labors can be referred to as migrant labors or migrants, temporary (foreign) labors or temporary migrants.

This mobility includes the crossing of a national border which takes on a character of immigration, whether temporary or permanent. Eventually, these labors are referred to as non-permanent or temporary foreign labors, temporary immigrants or guest workers, if they are regular/legal migrants. Previous researchers have provided important knowledge to the migration literature with regards to the differences in the way migrants negotiate the ongoing intercultural contact in the new society depending on their reasons for migration (Cobb-Clark, 2000; Horgan, 2000; Knipscheer et al., 2000; Tharmaseelan, 2005).

\section{International Migrant Labors in Tourism and Hospitality Industry:}

According to the World Tourism Organization (WTO, 2011), migrant labors play vital roles in contributing to the tourism economy of countries. Several studies indicate that the hospitality and tourism industry has historically relied on migrant workers (Christensen-Hughes, 1992; King, 1995; Janta et al., 2011; Baum, 2012). Further, Janta et al. (2011) also emphasize that migrant tourism labors make work and a casual lifestyle as a combination by engaging in seasonal employment as well as having entertainment and gain life experiences in tourism. Lee-Ross and Pryce (2010) in their study also note that one of the complexities of tourism and hospitality employment is that establishments that may have a mainstay of domestic and international tourists will also be used by locals, especially during the off season.

Cukier-Snow and Wall (1993) in their study indicate that migration to tourism areas bring up urbanization with its large potential for adverse effects such as congestion, inflated land prices, modified social organizations and changes in cultural values. The findings are similar to the earlier study by Cleverdon (1979). In addition, the high numbers of new jobs created by tourism in Kenya is fulfill by the large numbers of migrants who sought work within the tourism sector, hence the regional unemployment remained high (Harrison, 1992). It is claimed that a mutually convenient relationship exists when employers are willing, and some cases actively seek to employ migrants to fill the jobs unwanted by locals. Similarly, Monk and Alexander (1986) highlight that migrants to Margarita Island, Venezuela, are the main beneficiaries of tourism-generated employment, since many of the newly-created jobs were either inaccessible to the poorer segments of the local population or unattractive to the better off segments.

\section{Pull Factors Motivating International Migrant Labors:}

Migration research has proposed two main factors that are generally evident in the motives that lead migrants to leave their country of origin, namely, pull and push factors (Ward et al., 2001). Piore (1979) develops a theory on pull factor named as structural dependence which explain the evolution of attitudes of workers toward jobs, and adaptations of employers to immigrant workers. The theory also based on the notion that there is a hierarchy of jobs that changes slower than do worker aspirations which consequently explain how particular industries or entire economies come to rely on immigrant workers. The pull factors refer to wages, benefits, job opportunities, better facilities and promotion opportunities which attract people from one place to another.

Various definitions of pull factor derived accordingly to various researchers. For instance, Ward et al. (2001) define pull factors as contributing to voluntary migration and proposed that immigrants are pulled or attracted towards the new country in pursuit of personal, familial, social, financial and/or political goals. Ngamo and Ismail (2013) on the other hands, emphasize that pull factors may encourage and attract migrants into their preferred destination. Thus, it is important to understand the meaning of pull factor as motivational factor in terms of different perspective.

Pull factor is also defined as element which attract the migrants to an area such as opportunities for better employment, higher wages, better facilities, good working conditions and amenities (Kainth, 2009). It means people migrate to certain destination due to the factors which that particular destination provided. Similarly, the pull factor is also considered by Zopiatis et al. (2014) as the positive attitudes individuals see which motivating them to migrate to a particular destination. Additionally, the pull factors are also categorized into three factors namely economic, social, and political. Hajek (2008) considers the pull factor as absolute factor in compelling immigration in receiving countries that have a chronic and inevitable need for foreign labors.

According to the International Labor Organization (ILO, 1998), there are several factors that pull the international migrant labors to work in the tourism and hospitality industry such as running away from war, natural disaster and political instability. Additionally, the migration factors are usually tied to economic aspects for instance poverty and high rate of employment. Ngamo and Ismail (2013), in their study also include these factors practically absent in developing countries but readily available and obtainable in destination countries. Muhammad Azam (2015) highlights that pull factors in some cases are considered as positive aspects for the country of origin and for the country of destination such as the attractions for jobs, labor demand, improve education, health facilities, friendly working environment, better wages, improve standards of living, political and religious freedom.

In a previous study by Aiken et al. (2004), the pull factors which motivate people to migrate to other countries are noted as higher wages, better living and working conditions, and opportunities for advancing the education and expertise. Similarly, a study conducted by Reddy et al. (2004), also noted that an increase in income level and higher standard of living as well as better social and economic opportunities such as education, health, and job opportunities are pull factors which motivate labors from Fiji to migrate to Australia, New Zealand, Canada and United States.

Further, Findlay (2002) suggests several factors for instance better wages and employment conditions as motivational aspects which pull the international migrant labors and encouraging them to seek jobs in developed countries. In addition, Bodvarsson and Berg (2009) emphasize that few factors namely high salaries, opportunity for professional growth, job security and high standard of living as pull factors which promote international migration moving to other countries. The study is also supported by Wickramasekera (2002) where high wages is the answer of why people migrate in the first place.

A study by Kainth (2009) in Punjab State indicates that pull factors play dominating role in labor migration. The study concludes that two major pull factors emerge as significant pull factors which motivate migrant to work in particular country namely better employment opportunities and better living conditions. High 
wages offered by the industry is also considered as one of the pull factors in the better employment opportunities whilst the amenities provided by the industry is considered as factor in the better living conditions.

Several other studies also indicate the importance of understanding the pull factors motivating international migrant labors. For instance, Khoo et al. (2007) emphasize several pull factors motivating international migrant labors such as career development and better employment opportunities. Additionally, Lowell and Findlay (2001) consider pull factors as better wages, employment conditions, better information, recruitment and cheaper transportation. These factors are believed to encourage skilled migrants to seek jobs and opportunities in developed countries. High wages which is considered as monetary factor is also highlighted as vital factor which motivate hotel employees to stay with their jobs (Kiruthiga and Magesh, 2015).

In contrast, Datta (2004) emphasizes and focuses on economic opportunities in terms of job availability and political stability as pull factors which motivate the migrant labors to work in West Bengal. The study has involved several major pull factors namely economic, demographic, social, geographic and political/religious. Job opportunity and better economic opportunity are categorized as pull factors in the economic aspect. Additionally, the political stability in the countries they migrate is considered as pull factor in the political aspect. It is also noted that strong economic growth rate, harmonious community, better working, better living condition and higher wages are among factors that motivate the international migrant workers to work in the tourism and hospitality industry (Marwan, 2011). A recent study conducted by Mohd.Shariff and Abd. Ghani (2016) acknowledged that among the pull factors motivating international migrant labors to migrate are high salaries/wages, better job opportunities and high health benefits.

Methodology and Findings:

Methodology:

The study is considered as the first stage to understand the pull factors motivating international migrant labors to work in the tourism and hospitality industry. Hence, it involved an exploratory research where related and significant literature on the topic were critically reviewed. Further, it also included secondary data and information from report and statistical analysis prepared by specific organization concerning international migrant labors.

Findings - The Framework:

Based from the review of previous literature, five pull factors are identified as factors motivating international migrant labors to work in the tourism and hospitality industry namely high wages, better employment, better facilities, career growth and job security. The framework is presented in Fig. 1.

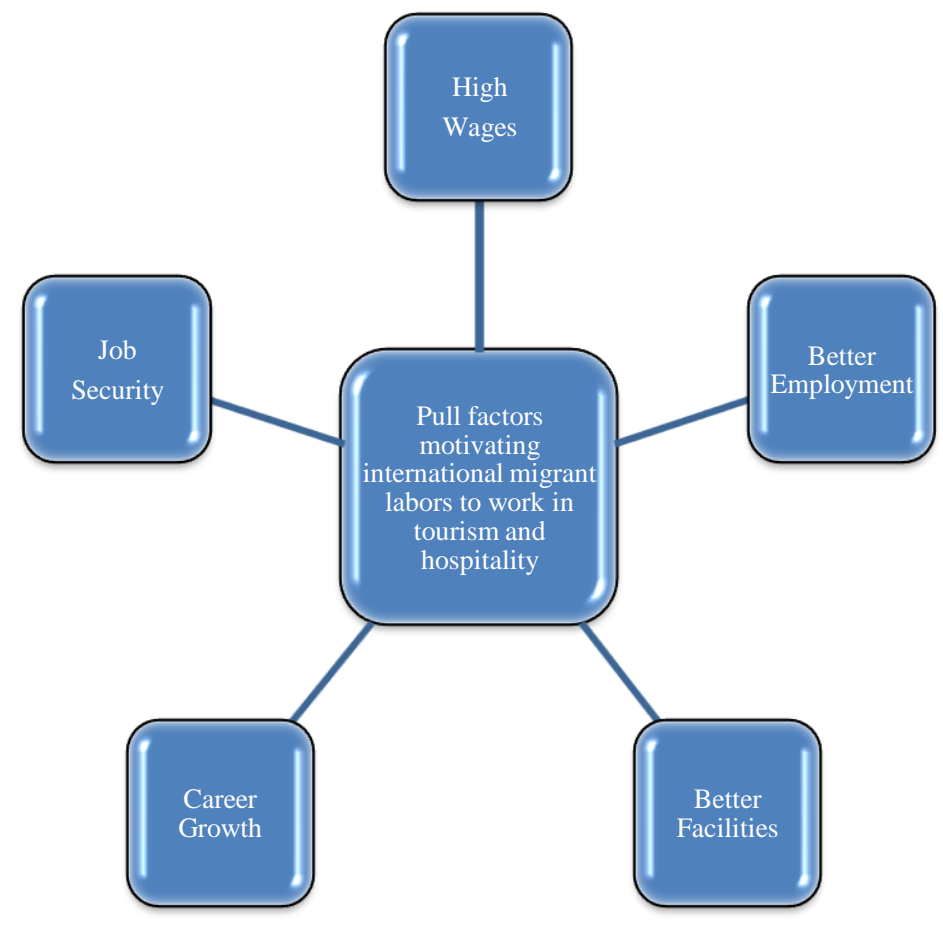

Fig. 1: Framework of pull factors motivating international migrant labors to work in the tourism and hospitality industry

The pull factors are consistent to several studies for instance Findlay (2002), Wickramasekera (2002) and Bodvarsson and Berg (2009). As concluded by Findlay (2002), high wages offered by the industry are among the factors which pull the international migrant labors. In this case, high wages might be referred by specific international migrant as better wages given by the industry compared to their own countries. The finding is also supported by Wickramasekera (2002) where better wages is seen as major pull factor motivating the international migrant labors to work in the tourism and hospitality industry. Additionally, the findings are also in line with other studies which indicate that better employment and better facilities offered by the tourism and hospitality industry as pull factors motivating the international migrant labors (Khoo et al.; 2007; Marwan, 2011).

\section{Conclusion:}

Discussion:

This paper highlights several pull factors which motivate the international migrant labors to work in the tourism and hospitality industry based from the review of related literature. It is noted that five aspects are considered as important pull factors motivating the international migrant labors to work in the industry. These factors are known as high wages, better employment, better facilities, opportunity for career growth and job security. Based on the previous literature regarding international migrant labors, it is noted that there might have been several factors motivating them to work in the tourism and hospitality industry. However, most literature highlight that the international migrant labors are moved by high wages offered by the industry. For some of them, their countries may not be able to offer such wages which they can consider as good enough to support their families. Being a seasonal employment industry, tourism and hospitality could highly cater for more international migrant labors to work in the industry.

Looking at better employment as pull factor, the international migrant labors may have considered it as an opportunity for them to work in the industry compared to other industries. This is probably due to the fact that the tourism and hospitality industry need a large number of workers to fulfill various sectors and departments. Hence, the employment of local labor may not be sufficient to cater the issue of labor shortages within the industry. Another factor considered as pull factor motivating them to work in the industry is the better facilities provided by the industry. This may be as vital pull factor taking into account by the 
Citation: Mohd. Shariff, N., Zainol Abidin, A., Abd. Ghani, N., Titing Kartika, 2018. International Migrant Labors in Tourism and Hospitality: Developing a Framework of Motivational Pull Factors. Australian Journal of Basic and Applied Sciences., 12(5): 47-51.

international migrant labors when migrated to the industry. Being away from their home countries, they want to choose the industry which would be able to provide them with facilities for instance accommodation, transportation, meal and many more.

Additionally, the international migrant labors also found that working in the tourism and hospitality industry can fulfill their career growth and guarantee job in a long term. They have opportunity to be employed in the industry since the local prefer to work in other service industry which is not seasonal and does not have shift operational working hours. Additionally, the framework may assist the industry to plan and manage the recruitment process particularly in selecting international migrant labors to fulfill the right positions at the right sectors without having to discriminate the locals. Based on the framework, further research should be conducted to interview international migrant labors as respondents with critical statistical method to assess whether the pull factors significantly motivate and influence them to work in the tourism and hospitality industry.

Contribution:

Theoretically, the study contributes in determining the vital pull factors which motivate international migrant workers to work in the tourism and hospitality industry. The findings also contribute to a comprehensive debate with valuable assistance and information for future purposes in managing international labor migration particularly in the tourism and hospitality industry. At the same time, the framework may also provide the tourism and hospitality planners and private sectors valuable information on the pull factors which may be used in the planning of incoming international migrant labors who may be able to contribute to the quality of work and employment stability in the sectors.

\section{ACKNOWLEDGEMENT}

Our appreciation goes to the Research and Innovation Management Centre, Universiti Utara Malaysia and School of Tourism, Hospitality and Event Management for their continuous support.

Funding information:

This study is sponsored by the Ministry of Higher Education Malaysia under the Fundamental Research Grant Scheme (FRGS) S/O code 13029.

Conflict of interest:

The authors have no conflict of interest in the study.

\section{REFERENCES}

Aiken, L.H., J. Buchan, J. Sochalski, B. Nichols and M. Powell, 2004. Trends in international nurse migration, 3(3), 69-77. Retrieved from http://doi.org/10.1377/hlthaff.23.3.69 on February 2014.

Ajis, M.N., M.F. Keling, Z. Othman and M.S. Shuib, 2014. The dilemma of managing foreign workers in Malaysia: opportunities and challenges, Global Journal of Human Social-Science:Political Science., 14(4): 43-53.

Athukorala, P., 1990. International contract migration and the reintegration of return migrants: The experience of Sri Lanka. The International Migration Review, 24(2): 323-346. Retrieved from http://www.jstor.org/stable/2546554 2014.

Baum, T., 2012. Migrant workers in the international hotel industry. 112. 1-49. Retrieved from http://www.ilo.org/sector/Resources/publications/on June

Bodvarsson Örn, B., V. Berg Henrik, 2009. The Economics of Immigration. Theory and Policy, Springer: New York, NY.

Cerdin Jean-Luc, M.A. Diné and C. Brewster, 2014. Qualified immigrants' success: Exploring the motivation to migrate and to integrate. Journal of International Business Studies, 45: 151-168.

Choi, J.G., R.H. Woods and S.K. Murrmann, 2000. International labor markets and the migration of labor forces as an alternative solution for labor shortages in the hospitality industry. International Journal of Contemporary Hospitality Management, 12(1): 61-67.

Christensen-Hughes, J., 1992. Cultural diversity: the lesson of Toronto's hotels. The Cornell Hotel and Restaurant Administration Quarterly, $33(2)$ : 78-87.

Cleverdon, R., 1979. The Economic and Social Impact of International Tourism on Developing Countries. The Economist Intelligence Unit: London.

Cobb-Clark, D.A., 2000. Do selection criteria make a difference? Visa category and the labour market status of immigrants to Australia. Economic Record, 76(232): $15-31$

Connell, J., 1987. Migration, rural development and policy formation in the South Pacific. Journal of Rural Studies, 3(2): 105-121.

Cukier-Snow, J. and G. Wall, 1993. Tourism employment. Perspectives from Bali. Tourism Management, 14: 195-201.

Datta, P., 2004. Push-pull factors of undocumented migration from Bangladesh to West Bengal: a perception study. The Qualitative Report, 9(2): 335-358.

Retrieved from http://www.nova.edu/ssss/QR/QR9-2/datta.pdf

Findlay, A., 2002. From brain exchange to brain gain: policy implications for the UK of recent trends in skilled migration from developing countries. International Migration Papers No. 43, International Labour Office, Geneva.

Hajek, P., 2008. Migrant workers in South East Asia: economic and social inequality in Indonesia, Malaysia and Singapore. Electronic Theses and Dissertations.Retrieved from:http://stars.library.ucf.edu/etd/3745

Harrison, D., 1992. International tourism and the less developed countries: the background. In Harrison D (Eds). Tourism and the Less Developed Countries, 1-18. Belhaven Press: London.

Horgan, O., 200. Seeking refuge in Ireland: Acculturation stress and perceived discrimination. In MacLachlan M and O'Connell M (Eds.), Cultivating pluralism: Psychological, social and cultural perspectives on a changing Ireland, pp. 60-85. Oak Tree Press: Dublin, Ireland.

ILO., 1998. International Labor Organization - International labour migration statistics database in ASEAN. Retrieved from www.ilo.org/asia/WCMSon December 2014. 2014.

IOM., 2010. International Organizational for Migration - World Migration Report 2010. Retrieved from www.iom.int/world-migration-2010on December

Janta, H., A. Ladkin, L. Brown and P. Lugosi, 2011. Employment experiences of Polish migrant workers in the UK hospitality sector. Tourism Management, 32(5): 1006-1019.

Kainth, G.S., 2009. Push and pull factors of migration : a case of Brick Kiln industry of Punjab State, Asia-Pacific Journal of Social Sciences, I(1): 82-116.

Khoo, S.E., P. Mcdonald, C.Voigt-graf and G. Hugo, 2007. A global labor market: Factors motivating the sponsorship and temporary migration of skilled workers to Australia. International Migration Review, 41(2): 480-510.

King, R., 1995. Tourism, labour and international migration, In Montanari A and Williams AM (Eds), European Tourism: Regions, Spaces and Restructuring, 177-90, Wiley: Chichester.

Kiruthiga, V. and R. Magesh, 2015. Gravity of job based determinants among different levels of star category hotel employees. Australian Journal of Basic and Applied Sciences, 9(10): 266-272.

Knipscheer, J.W. and J. Kleber, 2007. Acculturation and men health among Ghanaians in the Netherlands. International Journal of Social Psychiatry, 53(4): 369-383.

Knipscheer, J.W., E.E.M. De Jong, R.J. Kleber and E. Lamptey, 2000. Ghanaian migrants in the Netherlands: general health, acculturative stress and utilization of mental health care. Journal of Community Psychology, 28(4): 459-476.

Lee-Ross, D. and J. Pryce, 2010. Human resources and tourism. Skills, culture and industry. Channel View Publications: Bristol.

Marwan, NurFakhzan, 2011. Macroeconomic impacts of immigration in Malaysia: trade, remittances and unemployment. Durham theses, Durham University. Available at Durham E-Theses. Available online: http://etheses.dur.ac.uk/1411/ 
Citation: Mohd. Shariff, N., Zainol Abidin, A., Abd. Ghani, N., Titing Kartika, 2018. International Migrant Labors in Tourism and Hospitality: Developing a Framework of Motivational Pull Factors. Australian Journal of Basic and Applied Sciences., 12(5): 47-51.

Massey, D.S., J. Arango, G. Hugo, A. Kouaouci, A. Pellegrino and J.E. Taylor, 1993. Theories of international migration: a review and appraisal. Population and Development Review, 19(3): 431-466.

Mayda, A.M., 2007. International migration: a panel data analysis of the determinants of bilateral flows.Centre for Research and Analysis Migration Discussion Paper. Department of Economics, University College London.

Mejia, A., H. Pizurki and E. Royston, 1979. Physician and nurse migration: Analysis and policy implications. World Health Organization: Geneva, Switzerland.

Mohd. Shariff, N. and N. Abd. Ghani, 2016. A conceptual framework on issues and challenges of international migrant labors in Malaysia.Australian Journal of Basic and Applied Sciences, 10(11): 16-23.

Mohamed, B., S. M. Paisar and F.H. Mohd Nain, 2016. The impact of foreign workers to Malaysian tourism sector. In the Proceedings of 20 ${ }^{\text {th }}$ IASTEM International Conference, Sydney, Australia, pp: 33-35.

Monk, J. and C. Alexander, 1986. Free port fallout: gender, employment, and migration on Margarita Island. Annals of Tourism Research, 13 : $393-413$.

Muhammad Azam, 2015. The role of migrant workers remittances in fostering economic growth. International Journal of Social Economics, 42 (8): 690-705.

Ngoma, A.L. and N.W. Ismail, 2013. The determinants of brain drain in developing countries.International Journal of Social Economics, 40(8): 744-754. 292.

Patricia, R.P., 2010. Migrant workers' rights and status under international law: the Asian experience. Journal of East Asia \& International Law, 3(2): 263-

Piore, M.J., 1979. Birds of passage; Migrant labor and industrial societies. Cambridge University Press: New York.

Rachbini, D.J., 1991. Some reflections on dualism in the urban informal economy. Prisma, 51: 46-59.

Ramasamy, P., 2014. International migration and conflict: foreign labour in Malaysia. In Aris Ananta and EviNurvidyaArifin (Eds.). International Migration in Southeast Asia. pp: 273-295. Institute of Southeast Asian Studies: Singapore.

Reddy, M., M. Mohanty, M. and V. Naidu, 2004. Economic cost of human capital loss from Fiji: implications for sustainable development. International Migration Review, 38(4): 1447-1461.

Sharpley, R. 1994. Tourism. Tourists and Society. ELM Publications: Cambridgeshire.

Tharmaseelan, N., 2005. Careers in cross-cultural context: A study of Sri Lankan immigrants in New Zealand. Unpublished doctoral dissertation, Massey University, Auckland, New Zealand.

United Nations, 2009. World population prospects, economic and social affairs population division report, Table A.1, 2008 revision, United Nations, New York, NY.

Varley, C.G., 1978. Tourism in Fiji: some economic and social problems. University of Wales Press: Wales.

Vettori, S., 2017. The exploitation of migrant labor in the hospitality industry in South Africa. African Journal of Hospitality, Tourism and Leisure, 6(4): 1-

12.

Ward, C., S. Bochner and A. Furnham, 2001. The psychology of culture shock (2nd ed.). Routledge: Hove, UK.

Wickramasekera, P., 2000. Asian labour migration: Issues and challenges in an era of globalization. A report for International Migrant Office, Geneva. 1-48.

Williams, A. and C.M. Hall, 2000. Tourism and migration: new relationships between production and consumption, Tourism Geographies, 2(1): 5-27.

WTO, 2011. World Tourism Organization- International tourism 2010: Multispeed recovery. Press release. Madrid, ES: World Tourism Organization.

Yee, Y.S. and J.L.F. Yuen, 2014. The recruitment of migrant workers in the food service industry in Malaysia. A study of Old Town White Coffee and Pappa

Rich Kopitiam. International Journal of Business, Economics and Management, 1(10): 291-304.

ZainolAbidin, A., N. MohdShariff, A. Mohd Ibrahim and N. Yusof, 2016. Corporate governance in Malaysian tourism small and medium-sized enterprises: review of research issues. Australian Journal of Basic and Applied Sciences, 10(11): 236-242.

Zopiatis, A., P. Constanti and A.L. Theocharous, 2014. Migrant labor in hospitality: The Cyprus experience. International Journal of Hospitality Management, 37: 111-1. 